\title{
The Significance of Journal Writing in Improving Listening and Reading Comprehension in Modern Standard Arabic (MSA)
}

\author{
Inaam Saad*, Magdi Ahmed \\ Defense Language Institute, Foreign Language School, USA
}

Copyright (C) 2015 by authors, all rights reserved. Authors agree that this article remains permanently open access under the terms of the Creative Commons Attribution License 4.0 International License

\begin{abstract}
This paper investigates the effect of daily journal writing on enhancing the listening and reading comprehension skills in a fifty-week Modern Standard Arabic course taught at the Defense Language Institute (DLI) in Monterey, California. In the field of foreign language (FL) teaching, writing has long been considered a supporting skill for reinforcing new grammatical concepts and recycling vocabulary at the sentence level, (Kepner, 2011) although some academics rule out grammar correction as ineffective in facilitating improvement in students writing claiming that "grammar correction has no place in writing courses and should be abandoned" (Truscott, 1996, p. 328). However, researchers found other practical and effective uses for writing in improving proficiency in FL. The overall results of three Modern Standard Arabic classes, the subject of this study, were examined to establish whether the variable of journal writing is effective. Two classes out of the three were the experimental group and the third was the control group. This study examines influence of daily journal writing on the In-Course Proficiency Tests (ICPT) ${ }^{1}$ and the final Defense Language Proficiency Test-5 (DLPT-5) ${ }^{2}$ for the three classes. The findings showed that students' listening and reading comprehension skills in the six ICPT tests and final DLPT-5 test evidently correlated with the progress in students' writing skills. Statistics also revealed apparent improvement in the listening and reading comprehension skills of struggling students in the two experimental classes compared to the control class.
\end{abstract}

Keywords Modern Standard Arabic, Journal Writing, Foreign Language (FL) Teaching

1 These are graded in-course proficiency tests. They are similar to mid and final tests for each semester.

2 The Defense Language Proficiency Test, Version 5 (DLPT-5) is produced by the Defense Language institute and used by the Department of Defense. It assesses the language proficiency of students in listening and reading and uses authentic materials in testing to test up to level 4.

\section{Introduction}

Journal writing is an instructional and learning tool which is used in various ways in foreign language teaching. Many FL educators use journal writing for enhancing FL learning and language fluency development. There are a number of potential benefits for learners in journal writing such as enhancing students' intellectual growth and knowledge through research (Mlynarczyk, 1998, p. 18). It is an ideal way of shaping and reinforcing language patterns through self-expression using the inner speech. "Asking students to keep a journal is a natural way for teachers to encourage the human pattern-forming propensity" (Mlynarczyk, 1998, p. 21). In the course of this study, it was observed that journal writing helped students in their personal development and ability to examine new knowledge in critical ways. More benefits will be discussed in the "Correlation Justification" section.

This paper attempts to answer the following questions: 1) does daily journal writing enhance reading and listening skill? 2) If yes, then to what extent does it augment these two skills, and 3) what are the mechanisms and reasons behind this influence? To achieve its objective, this study examines the data of all the achievement and proficiency tests of the Arabic Basic Course (ABC) curriculum at the DLI. It endeavors to establish and measure the impact of daily journal writing on enhancing the listening and reading comprehension using the results of unit tests, ICPT tests, and the DLPT-5.

The two experimental classes I \& II graduated in July 2011 and August 2012 respectively; the control class graduated in July 2013. All classes graduated with zero percent academic attrition ${ }^{3}$. The teaching team received the Provost's Excellence Award in July 2011 and the Commandant's Coin of Excellence in November 2012 for

3 Academic attrition is defined as "a student permanently leaving an academic program prior to the program's scheduled end date" mostly due to repeated failures or poor performance. (DLIFLC Reg. 350-10, 29 August 2013). 
the results of the two experimental classes. The first of the two experimental classes graduated with $100 \%$ passing rate in listening, reading and speaking (more than $50 \%$ level $2+$ and level 3 in listening and reading, and $66 \%$ level 2 in speaking). The second of the two experimental classes graduated in July 2012 with 100\% speaking level 2, 71\% listening and $86 \%$ reading (with more than $50 \%$ level $2+$ and level 3). The third class, the control class, graduated with $50 \%$ in listening (with $0 \%$ level $2+$ and level 3 ), $66 \%$ in reading (with $50 \%$ level $2+$ and level 3 ), and $100 \%$ in speaking at level $1+$ (with $0 \%$ level 2 and level 3 ).

The following table illustrates in percentages the results of the three classes.

\begin{tabular}{|c|c|c|c|}
\hline The Class & Listening & Reading & Speaking \\
\hline $\begin{array}{c}\mathrm{AD} 00410 \\
\text { Experimental I }\end{array}$ & $\begin{array}{c}100 \% \text { Level } \\
1+\end{array}$ & $\begin{array}{c}100 \% \text { Level } \\
1+ \\
\text { More than } 50 \% \\
\text { L } 2+\& 3 \\
\end{array}$ & $\begin{array}{c}100 \% \text { Level } \\
1+ \\
\text { More than } \\
66 \% \text { L } 2 \\
\end{array}$ \\
\hline $\begin{array}{c}\text { AD00411 } \\
\text { Experimental II }\end{array}$ & $\begin{array}{c}71 \% \\
\text { More than } 50 \% \\
\text { L2+\& } 3\end{array}$ & $\begin{array}{c}86 \% \\
\text { More than } 50 \% \\
\text { L 2+\& } 3)\end{array}$ & $\begin{array}{c}100 \% \\
100 \% \text { Level } 2\end{array}$ \\
\hline $\begin{array}{l}\text { AD00412 } \\
\text { Control }\end{array}$ & $\begin{array}{c}\% 50 \\
(0 \% \text { L } 2+\& 3)\end{array}$ & $\begin{array}{c}\% 66,7 \\
50 \% \text { L } 2+\& 3\end{array}$ & $\begin{array}{c}100 \% \text { Level } \\
1+ \\
0 \% \text { Level } 2\end{array}$ \\
\hline
\end{tabular}

It is worth mentioning here that the academic standing of the control group was not negatively impacted by depriving them of an essential tool of success. Its journal-free course was the structured, standardized Master Educational Plan provided by the DLI without adjustments. Journal writing was introduced to the other two experimental groups as an intervention that would potentially leverage students' performance.

\section{Objectives of the Study}

The purpose of this study is to examine the following:

a) The relationship between journal writing and the listening and reading skills.

b) If the overall language proficiency in Modern Standard Arabic correlates with journal writing practice continuum.

c) The impact of journal writing on the in-course high stakes tests and the final DLPT-5.

In particular, the study addresses the following questions:

a) Does daily journal writing help students improve their performance in the course achievement and proficiency tests?

b) Is listening enhanced by journal writing more than reading?

\section{Establishing the Need for Journal Writing}

DLI curriculum focuses on Final Learning Objectives (FLO) topics with the intent of producing linguists with specialized linguistic and intellectual skills. Both of the final test and the on-job duties of students do not only require strong command of Arabic but also critical thinking and problem solving skills.

The curriculum includes homework books tailored for reinforcing the content of every chapter. This homework is a part of the curriculum and covers 10 units only out of 14 units in the $\mathrm{ABC}$ curriculum, leaving 4 units without reinforcement of the learning content.

In semester one and two, the homework book does emphasize the learned content but rarely emphasize creativity. Creativity can be enhanced through journal writing. Journal writing provides students with free and limitless horizons to project their views on the learned content through giving them the opportunity to express themselves and inject their personal experiences. In semester three, students need to use their higher level thinking skills of analyzing, synthesizing, evaluating, creating, critiquing, etc. Journal writing at this stage bridges the gap between their knowledge of Arabic and their ability to utilize it in tackling high level linguistic tasks like the DLPT-5 test and later their on- job duties.

\section{The Method and Data Collection}

No random selection was made for this study because it was not planned for or intended before the classes started. There was no intent to do research or publish the outcome at the time of introducing the intervention of journal writing for the purpose of improving students' performance. What prompted this paper were the striking patterns of improvement in students' performance either throughout the course or at the final test. It was simply noticed that three classes, graduated in three different consecutive years--a year for each class, had similar constants but different results. The improved results of the first two classes correlated with the introduction of journal writing. The third class had constants as the experimental class in terms of students' characteristics, curriculum, length of course, students' age, previous education, and the same teaching faculty, but does not have the assignment of daily journal writing. The first two classes are naturally occurring experimental group although it was not meant as experimental at the time of introducing the journal writing. For simplification, the terms "experimental" and "control" classes will be used.

Data in this study was collected anonymously: students' names were not sought in the process of writing this paper or analyzing its data; class numbers are only provided.

This study is based on generalized knowledge that may or may not necessarily work for other similar classes. Although this study is in line and conformity with the pedagogical classroom practices in the field of second language teaching, further research and larger scale data and analysis are needed to confirm and warrant the conclusion of this study.

\section{Participants}


The participants were enrolled in three fifty-week MSA classes. All of the students in the three classes had university education -- some had post-graduate studies. The female to male ratio was almost the same: about one third females in all classes. None of the students had previous language learning and their ages ranged from 29 to 35. All were motivated because success was essential to advancement in their careers and because they all were the breadwinners for their families. They all studied the Arabic Basic Course (ABC) curriculum which consists of 14 units that cover a variety of topics and levels ranging from level 1 to level 3 on the Interagency Language Roundtable (ILR) scale ${ }^{4}$. The two experimental classes practiced daily journal writing early in the course consistently throughout the ABC course on top of the mandatory writing assignments which were part of the course requirements. The control class did not practice any additional journal writing beyond the mandatory writing assignments. The three classes varied in number of students. So, percentage of the total number for each class will be used.

\section{The Process of Assigning a Journal}

The daily journal writing was one page which was typically hand-written in a notebook as a means of recording information, biography, descriptions, news reports, thoughts, reflections, feelings or personal opinions. Every assignment had its own instructions and objectives. Students were given guidance on the way they should write their journals.

The assigned writing topics varied with the theme of each unit in the curriculum and with the language structure (grammar, culture, and text level). One day a week students were given the assignment of listening to news articles about the Middle East or any other target-language country and writing a comprehensive summary about that news item. This listening-based journal varied in length, frequency and task by semester. In semester one and two, it was assigned one time a week and required students to relay the EEIs ${ }^{5}$ and inject their own personal opinions; in semester three, however, it was two times a week and required them to fulfill critical thinking tasks.
Students were asked to set a time limit for journal writing (40-60 minutes). All aspects of journal writing assignments were discussed and taken into account before assigning the journals. Journal assignments were meant to be effective, efficient and interesting. They were thought of as a learning continuum in which students have several opportunities to learn throughout the continuum chain. The cycle of learning starts with the appropriate selection of a journal scenario or topic with relevant instructions and criteria. Students research the topic, review vocabulary, grammar or culture related to the topic, reflect on the issue or topic, and form an opinion, assumption, impression or conclusion then express it in writing. Teachers give feedback with clues in the form of correction codes. Students research and discover their own errors and correct themselves then verify their corrections. They are often asked to share what they learned with fellow students. (Expanded under next section "Feedback and Assessment")

Journal writing assignments were designed to make students do the following:

a) Produce content that is real life and reflect their own views on the assigned journal establishing connections through personal experiences and observations to the writing topic and context (Hettich, 1990).

b) Define, rephrase, record, reproduce, repeat, or memorize words, sentences or paragraphs for journal assignments early in the course. These involved lower order thinking (LOT) skills for assignments early in the course.

c) Think, speculate, analyze, reflect, evaluate and imagine. Utilize higher order thinking (HOT) and problem solving skills to produce linguistically accurate, expressive journals. "Journal writing is often conductive to reflection" (Mlynarczyk, 1998. p. 19) and a "key factor in the ability to write reflectively is the development of one's thought process (Mlynarczyk, 1998. p. 18) and becoming aware of one's mental functioning introduces important new possibilities (Vygotsky, 1986, pp. 170-171). 


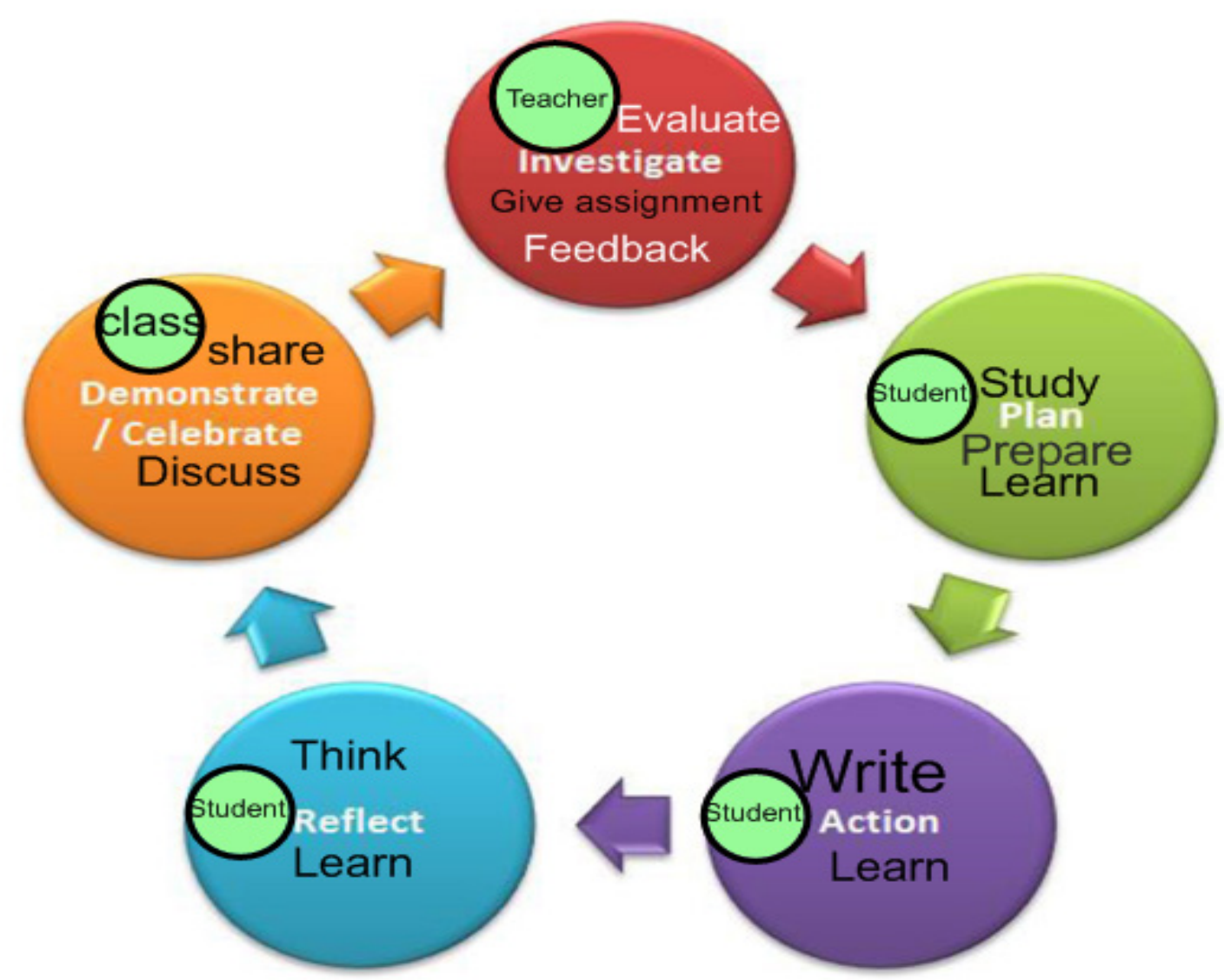

Graph 1. The Journal Learning Continuum. Journal writing is thought of as a learning continuum in which students have several opportunities to learn throughout the continuum chain.

\section{The Feedback and Assessment}

Journals were collected every day. Students received feedback on their entries in writing in the form of "correction codes" that gave them clues to their mistakes. They were asked to contemplate on their own mistakes, figure out the corrections using the codes then present the corrections the next day. If it was a spelling mistake, they were asked to rewrite misspelled words until mastery; if it was a grammatical error, they were expected to state what the mistake was, what the metacognitive rule about it is, then produce more correct structures. Sometimes, students were asked to share what they learned with their class explaining what their mistakes were, why they were wrong, and what the correction is. This helped fellow students avoid doing the same mistake and more importantly, it made students teach and brush on what they learned.

It was noticed that feedback helped students in the following ways:

- Built up their confidence.

- Motivated weak students to improve through learning from their own mistakes.

- Identified their strengths and weaknesses, especially the common mistakes which enabled the teaching team to design interventions, such as grammar clinics addressing specific grammatical features.

Assessing student's daily writings helped the teaching team achieve the following goals:

- Determining whether the intended outcome of any specific writing assignment was achieved.

- Providing the appropriate feedback and setting the appropriate writing standards to enable students to improve their performance

- Motivating students to take the initiative in creative and task-based writing.

- Evaluating the effectiveness of daily writing in improving students' performance.

Formative assessment was used to guide the development of journal assignments throughout the course in a way that matched the development of students' writing ability. Methods and criteria of assigning journals were adjusted with the progress of the course. In fact, the introduction of the correction codes was one of the adjustments.

\section{Results and Discussion}

The data was analyzed for the overall results of the three classes in the seven units' achievement tests and the six ICPT tests in addition to the final DLPT-5 and the OPI tests. The data reveals that journal writing started having an impact on enhancing reading and listening comprehension in the experimental classes; the control class had the lower percentage of students who passed in the two skills. It seems 
the intervention of journal writing started to show influence at unit four in listening and reading and as early as ICPT 102, around week 14 (of the 50 week course).

The results of the three classes were comparable throughout the first semester tests: all students equally achieved high levels in listening comprehension early in the course. The turning point is the mid-term exam in the first semester where the two experimental classes achieved higher percentages compared to the control class.
The two experimental classes achieved higher passing percentages on the comprehension tests throughout the second semester expect for the ICPT 201 where the three classes achieved $100 \%$ passing rate. The experimental classes continued to out-perform and over-achieve the control class throughout the third semester in all of the three skills of listening, reading and the oral proficiency test. The ultimate test results were achieved by the experimental classes in the final exam (DLPT-5)

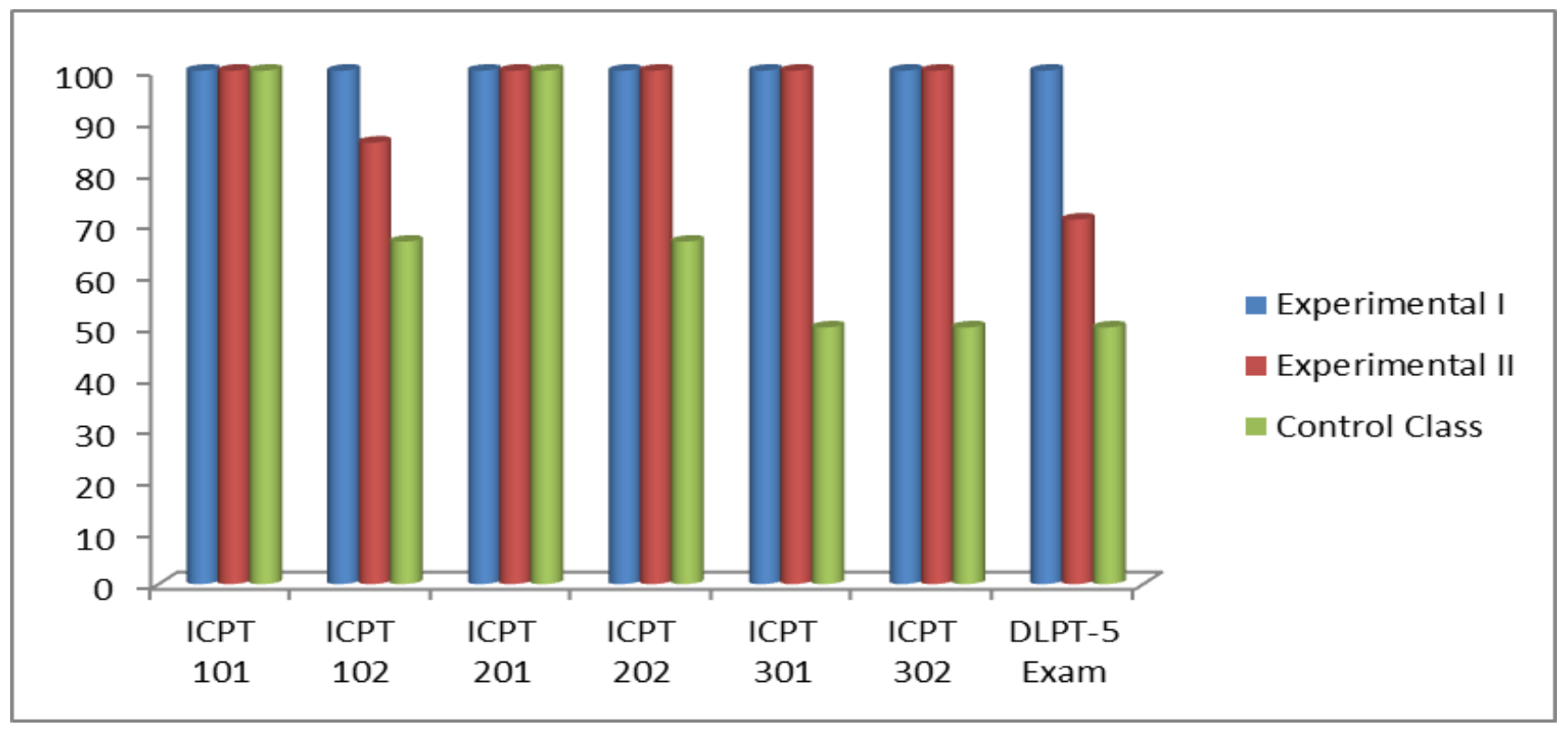

Graph 2. The reading results of all the ICPTs and the final DLPT-5

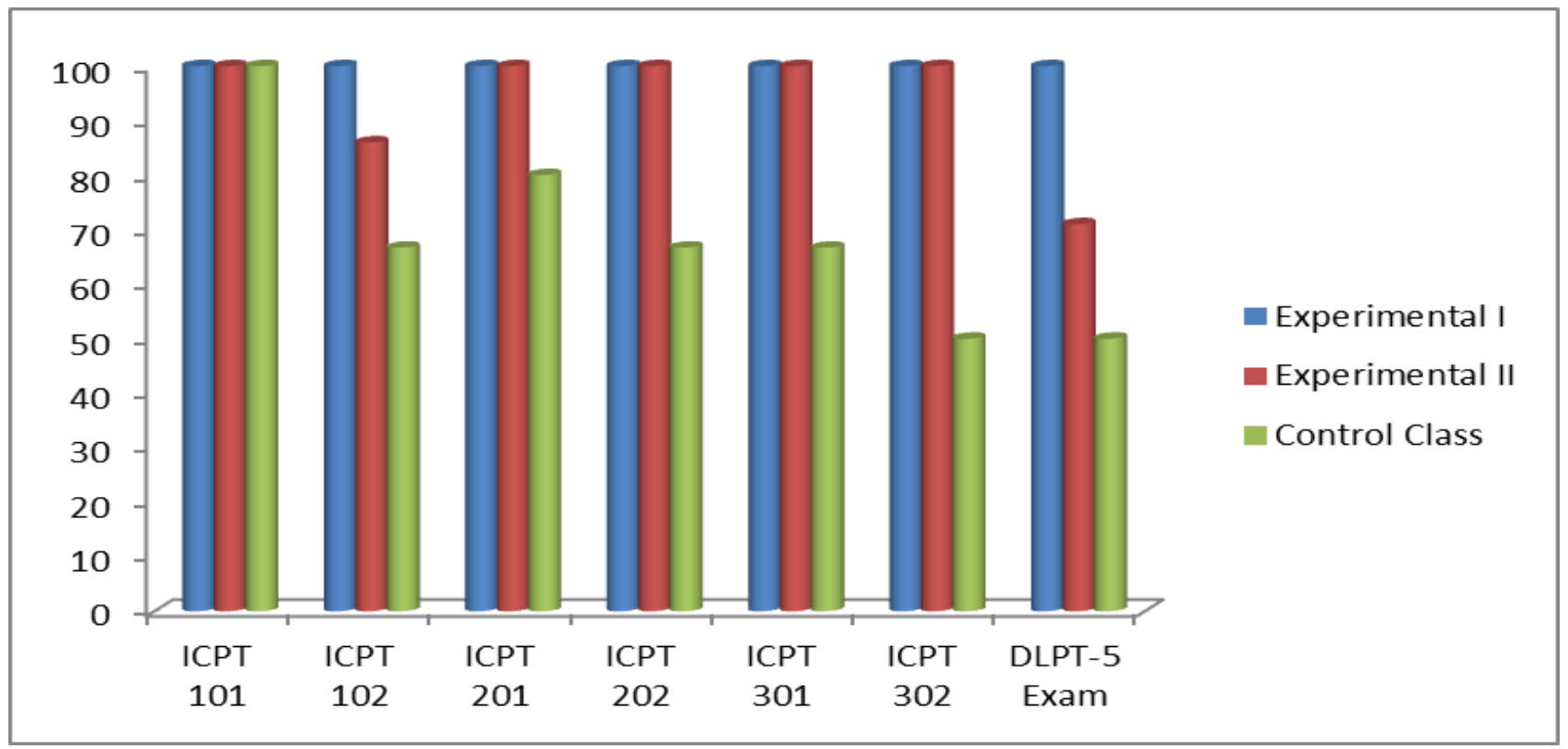

Graph 3. The listening results of all the ICPTs and the final DLPT-5 
The above graph shows that the two experimental classes achieved higher passing rate on the reading comprehension test compared to the control class throughout the third semester and the final DLPT-5 test. This graph uses the results of the ICPT tests only, not unit achievement tests because they reflect the real progress of students based on the ILR The passing grades are (A, B, or C, not including C-); Cor worse is a failing grade.

\section{Correlation Justification}

The following are the possible logical reasons that can shed light on and explain the impact of journal writing on the listening and reading skills as shown in the charts above.

1. In reading and listening activities, students tend to be passive learners of the language whereas in writing they are creators of the language who use multiple cognitive processes of language production.

2. Journal writing was, in part, listening-based and task-based. Students were given a topic-related listening assignment with the task of writing their input on what they listened to. To complete the task, they had to comprehend the listening beforehand. Because listeners tend to remember the content of a message rather than the exact words (Buck, p. 77) students were not asked to write using the exact words and sentences in the listening, but rather reflect, analyze and create language content using their own words.

3. To use topic-specific vocabulary, students had to look up new words, review chapter or unit glossary and refer to cultural events and expressions in order to support their points of view. In this pursuit, "for making sense, the writer is making knowledge" (Moffet, 1982 .237).

4. The use of journals in FL classroom has been found to directly enhance student's speaking and reading abilities (Barbara, 1993) "and help [students] become better readers"(National Council of Teachers of English, 2004); the reading ability, in turn, enhances the listening ability. It works like reactions in the law of Newton's Cradle collision balls. This is especially true in Arabic because if students can spell out a specific word and accurately read a phrase or a sentence, their abilities to recognize such word or sentence in both reading and listening format expands. If practiced as real authoring, journal writing will impact other skills and "instead of using writing to test other subjects, we can elevate it to where it teaches other subjects (Moffet, 1982 .237).

5. Journal writing forces students to think about forming structurally sound sentences in meaningful and contextualized episodes. It also enhances their ability to express and support their ideas in a well-organized and comprehensible manner which helps improve their language proficiency.
6. The criteria established and the measurable objectives set for journal writing helped maximize the benefits of writing and ensured that learning happens. The success of journal writing as an intervention depended on the achievement of these objectives which include:

a) Enabling MSA language learners to process the vocabulary in a meaningful context.

b) Increasing the active involvement of students in their own learning through "enabling learners to understand their own learning process" and "increase active involvement in learning and personal ownership in learning" (Moon, 1999, pp. 188-194).

c) Improving the quality of learning through encouraging critical and analytical thinking. Journal writing "deepens the quality of learning in the form of critical thinking or developing a questioning attitude" (Moon, 1999, pp. 188-194).

d) Providing an alternative means of communication for students who, for personality reasons or language difficulty, shy away from practicing speaking on a regular basis in the classroom. The use of dialogue journals in FL classes has been established as a practical method that helps learners write in the Target Language (TL) without fear of failure or ridicule (De Godev, 1994; Iventosch, 1988; Popkin, 1985).

e) Promoting reflective and creative interaction in the classroom through sharing experiences and dialogue journal.

f) Helping students explore different options to bridge the gap between classroom and real life scenarios.

7. In addition to the above-mentioned reasons and the traditional academic benefits such as recycling vocabulary and mastering grammatical structures, journal writing in FL learning has many benefits that help students in their personal, academic and intellectual life. It is a learning process that helps improve mental clarity and thinking: putting ideas and feelings in words helps clarify and define one's own identity and problems which paves the way to solving them. It is also used as a venting venue for students to express their thoughts about daily learning and "use it to explore issues related to the final exam" (Mlynarczyk, 1998. p. 49). An "important purpose the journal served for students was providing a socially acceptable outlet for their imagination and lively intelligence" (Mlynarczyk, 1998. p.69).

\section{Conclusions}

Journal writing had a compelling role in enhancing students' overall proficiency in the two MSA experimental classes. This enhancement is attributed that to the fact that 
second language learning is a continuum in which every step is essential. Learning happens when students discover their own mistakes and also discover the corrections for the mistakes. Learning is also augmented when students are encouraged to reflect on their journal assignments and think about the thinking and learning processes. Journal writing becomes effective when it is closely connected to the topics and concepts taught during the school day; it, then, reinforces the learning content. Data analysis in this study shows improvement in both reading and listening; while speaking was also enhanced, it was not included in this study. The study did not establish whether the listening skill was enhanced by journal writing more than reading or vice versa due to insufficient data.

\section{REFERENCES}

[1] Barbara, C. (1993) The Effect of Dialogue Journal Writing on the Speaking Ability of Students' in Spanish as a Foreign Language (Doctoral Dissertation, Penn State University, 1992). Dissertation Abstracts International, 53, 4304

[2] Buck, G. (2001). Assessing Reading. Cambridge: Cambridge University Press

[3] De Godev, C. B. (1994). A Rationale to Integrate Writing in the Foreign Language Conversation Class. (Eric Document Reproduction Service No. ED375679)

[4] Ferris, D. (1999). The Case for Grammar Correction in L2 Writing Classes: A response to Truscott (1996). Journal of
Second Language Writing, 8, 1-11

[5] Hettich, P. (1990). Journal-Writing: Old Fare or Nouvelle Cuisine. Teaching of Psychology 17:36-39

[6] Iventosch, M. S. (1988). Dialogue Journals: Students' Risk-Taking in Content and Form. Unpublished master's thesis, University of Arizona, Tucson, Arizona.

[7] Kepner, C. G. (2011). An Experiment in the Relationship of Types of Written Feedback to the Development of Second-Language Writing Skills. Article first published online: 20 OCT 2011

[8] Mlynarczyk, R. W. Conversations of the Mind: The Use of Journal Writing for Second-Language Learners. Laurence Erlbaum Associates, Inc.

[9] Moffet, J. (1982). Writing, Inner Speech and Mediation. College English, 44(3), 231-246

[10] Moon, J. A. (2006). Learning Journals: A Handbook for Reflective Practice and Professional Development, 2nd Ed. Routledge Falmer, New York, NY

[11] National Council of the Teachers of English, (2004). NCTE Beliefs about the Teaching of Writing. Urbana, Illinois. An online article published in the following link http://www.ncte.org/positions/statements/writingbeliefs

[12] Popkin, D. (1985). Dialogue Journals: A Way to Personalize Communication in a Foreign Language. Foreign language Annals, 18(2), 153-156

[13] Truscott, J. (1996). The Case against Grammar Correction in L2 Writing Classes. Language Learning, 46, 327-369.

[14] Vygotsky, L. (1986). Thought and Language (A. Kozulin, Ed.). Cambridge, MA: MIT Press. (Original Work published in English, 1962). 